\title{
Fostering Inter-Cultural Communication Skills among Learners through Teaching English as an International Language
}

\author{
Saeed Ahmad (Corresponding author) \\ English Language Centre, Jazan University, Saudi Arabia \\ E -mail: saeed edu@hotmail.com \\ Nazeer Ahmad \\ English Language Centre, Yanbu, Saudi Arabia \\ E-mail: rafiquen@rcyci.edu.sa
}

Received: 15-03- 2015

Published: 01-11- 2015
Accepted: 21-06- 2015

doi:10.7575/aiac.ijalel.v.4n.6p.52
Advance Access Published: August 2015

URL: http://dx.doi.org/10.7575/aiac.ijalel.v.4n.6p.52

\begin{abstract}
Inter-Cultural Competence (ICC) is a topic of hot debate in the educational circles since 1960s. The traditional models of Communicative Competence which focus on native speaker models fall short of making learners adjustable in the international settings. Fostering ICC through English Language Teaching (ELT) is a norm in the current scenario of globalization rather than exception, which the teachers and researchers in Applied Linguistics are trying to establish since quite some decades. This case study is the part of an empirical research taken with the objectives to explore the implications of developing ICC in the learners through teaching EIL. This paper draws on the need of EIL for the Saudi learners for which interviews with the selected teachers from English Language Centre of Jazan University (KSA) provided data. The results show a wide array of concerns for the learners and teachers, and the policy makers. Teachers are the most important factor in developing modalities of ICC in the learners. A locally modified curriculum is needed to implement EIL in the class room.
\end{abstract}

Keywords: Teaching English, International Language, Inter-Cultural Competence, Teachers' Training, Curriculum, Saudi Arabia

\section{Introduction}

The recent development in international education has highlighted the importance of ICC in the learners. ICC has been ranked higher than Chomskian LINGUISTIC COMPETENCE (1957), and Hyme's COMMUNICATIVE COMPETENCE (1971) because it is important for the learners to know 'when and how to say what to whom' (LarsenFreeman, 2000). Canale (1983) further elaborated this concept in four competencies: Grammatical Competence, Sociolinguistic Competence, Discourse Competence and Strategic Competence (Ahmad and Rao, 2012) which is indeed a native speaker model of language. These competencies provide a linguistic based frame of language which ultimately results in accurate production of language by the users. The Sociolinguistic Competence, however, is significant since the massive mobility of the people around the world is increasing over time. The study of interconnection between language and culture is an important outcome of teaching and learning other languages. And, there is ample proof of the fact that language-culture correlation is a must for an effective cross-cultural communication. This aspect of language learning and teaching has drawn attention of many researchers because language education in its very essence is instrumental. Although a plethora of research suggests its humanistic significance, yet it lacks in teaching how the correlation of language and culture actually works, and how to attain the goal of ICC through teaching EIL. Truly speaking, there is no unified code of ICC in the realms of language teaching. A universal framework is required which could maintain the true nature of ICC and on the other hand may elaborate how to achieve this target through teaching EIL. Some researchers have termed this situation as teaching English as an Inter-cultural Language (EIcL), like Sifakies (2004):

“The 'best' EIcL teaching situations are those that exhibit variety in the learners' cultural and linguistic backgrounds. This essentially means that classes whose learners' L1 are different serve better for EIcL tuition" (Sifakis, 2004).

\section{Background of the Study}

As opposed to the common notion, an international language is not the language with maximum number of speakers (McKay, 2002). McKay claims that an international language means that when it is no longer linked to a single culture or nation but (it) serves both global and local needs as a language of wider communication, and it is used by individuals 
who use English as a second language alongside one or more other languages they speak (p. 24-27). Considering the ever growing number of the users of English and great diversities found amongst its users, it is the need of the time to take more and more research in this direction. The native like proficiency in producing correct language is no more ideal, and it ceases to be the final goal of learning a target language for the international community. The coming years will witness the increasing number of bilingual users of English who, along with their mother language, will be using one or more other languages for a wider communication, business, academics, traveling, and so forth. To challenge 'native speakerism' (Holliday, 2006) is important to understand completely how English as a target language is learnt in various contexts... the concept of thinking globally but acting locally is highly relevant to the teaching of EIL (Mckay, 2002). She, however, says that to decide which variety of English is the standard one is quite controversial. In this respect, she gives credit to the levels of intelligibility, general attitudes of the users towards a target language, lexical features, pragmatic standards, rhetoric and phonological orientation of the language found among different varieties of English around the world today.

Teaching EIL is based entirely on different assumptions than Teaching English as a Second Language (TESL) and Teaching English as a Foreign Language (TEFL). EIL entails the situation of teaching to those individuals who have learned other language/s alongside their mother tongue for communication with the people of different languages and cultures, and they want to become a part of the global community. The status to a language being International is given when it no longer belongs to a certain nation or community; rather it serves the local and global needs of various nations and communities with multicultural context/s (Mckay, 2002).

McKay (2002) identified the following priorities for EIL (as mentioned in Seidlhofer, 2004):

- Ensuring intelligibility rather than insisting on correctness

- Helping learners develop interaction strategies that will promote comity (friendly relations)

- Fostering textual competence (reading and writing skills for learner-selected purposes)

- Sensitivity in the choice of cultural content in materials

- Reflexivity in pedagogical procedures

- Respect for the local culture of learning

English is serving as the number one Lingua Franca in the world today, and this status of language shows its capability of expression in the fullest sense of meaning.

"For better or worse, by choice or force, English has 'traveled' to many parts of the world and has been used to serve various purposes. This phenomenon has created positive interactions as well as tensions between global and local forces and has had serious linguistic, ideological, socio-cultural, political and pedagogical implications" (Sharifian, 2009).

Historically speaking, McKay (2002) attributed timing and good luck to the wide spread of English language besides some other factors like international economics, political awareness, historical back ground and geographical importance of some regions over others, and to the large scale emigrants across the world. Mckay (p. 27) while referring to Kachru's (1992) famous three circle classification of ESL and EFL in the World Englishes says that the needs of bilinguals in the outer circle and expanding circle countries differ greatly than from those living in the inner circle regions. Being that the users of English language in the outer and expanding circle countries outnumber than those in the inner circle countries, the international significance of English is quite obvious, and more research is needed so that English could serve the purpose of all of its users.

The fallacy of a superior native speaker model has already been challenged by many researchers in Applied Linguistics (like Sharifian, 2013; McKay, 2002). The current surge of research in this direction will hopefully lead to a detailed picture of English language that is acquired in varied contexts around the world to strengthen the idea of bilingual professionals for teaching EIL (McKay, 2002--P.45). The native speaker model is indeed "characterized by the belief that 'native-speaker' teachers represent a 'Western culture' from which springs the ideals both of the English language and English language teaching methodology” (Holliday, 2006, p 385-as mentioned in Renandiya, 2012). Sharifian's (2013) research highlights the global journey of English and he called this phenomenon as the 'GLOCALISATION' of English language. He said:

"The glocalisation of English and the dynamics of increased contact between people from different cultural backgrounds, or trans-cultural mobility, call for new notions of 'competence' to be applied to successful inter-cultural communication... ELT curricula should aim at developing competencies in learners that enable them to achieve success in intercultural communication with speakers from various cultural backgrounds.

\section{EIL in the changing Saudi context and globalization}

English, as a means of communication, is very important for the Kingdom of Saudi Arabia (KSA); for the business of its largest oil company (ARAMCO) within and outside the country; for military of KSA with the advisors from USA (Mahboob and Elyas, 2014) and other countries; and for dealing with millions of expatriate workers who are engaged with education, health, engineering and construction, international relations for living in harmony with others, and businessmen who play a vital role in the economy of the country. English in KSA is a Performance Based variety, as 
Al-Asmari (2015) puts it. Mahboob and Elyas (2014), while referring to many researchers and scholars in the Saudi context, emphasize on the significance of English communication for the Saudies, argue that (in KSA) "...oil and gas companies have started setting strict requirements for (intercultural) communicative competence in English for their workers, describing in detail the tasks and levels of attainment KSA workers need to achieve in order to reach the levels expected of particular positions. Business leaders and academics have also expressed concerns about the ability of KSA graduates to compete in the global economy and have recommended a focus on modernization, to include 'critical and creative thinking" ... and more and 'better' quality English instruction ( Al-Miziny 2010, Al-Hajailan 2003; AlSeghayer 2005).

The increasing interest of the Saudi government and its largest oil company (ARAMCO) in other countries, like China, Japan and South Korea, is a harbinger of massive change on the national front. Although Saudi Arabia has very close ties with the USA and their collision has played a pivotal role in shaping the Saudi economy and society, yet it is now felt by the experts that new avenues will be opened on national level which will reshape the economy and social behavior in Saudi Arabia (Wagner and Cafiero, 2014; Dimensions International, 2014). This is quite obvious from the recent development in the international relationships between KSA and other countries. ARAMCO has been reported to establish new bases in the far regions, especially in China, Japan and South Korea:

"The organization was officially inaugurated in November 2012. With offices in China, Japan and South Korea, Aramco Asia consists of three companies, Aramco Far East (Beijing) Business Services (ABS) Co., Aramco Asia-Japan (AAJ) and Aramco Asia-Korea (AAK), which are all owned by the Saudi Aramco Asia Co., and is wholly owned by Saudi Aramco" (Dimensions International, 2014).

The changing needs of Saudi Arabia demand for a shift from focusing on EFL to EIL at all levels. Broadly speaking, the context of Saudi culture has always been neglected in teaching English at all levels in KSA. The courses most of the time do not reflect the teachings of Islam, for an instance, on which the Saudi society is based upon. And, this issue has been raised on a number of forums by many scholars (for example, Karmani, 2006):

"The current designed English syllabus in the Arab world doesn't reflect the true aspiration of the Muslim Nation. It does not contribute to the right upbringing of a true Muslim generation. The English syllabus that we have in our educational institutions is completely based on the western culture which is totally different and far away from the Islamic teachings" (Karmani, 2006-as mentioned in Mahboob and Elyas, 2014).

\section{Interview Results}

Patton's 'maximum variation sampling' technique (Lincoln \& Guba, 1985) was adopted to assure maximum representation of the participants in interview. Berg (1989) presented three kinds of interview: the formal or standardized interview, the informal or un-standardized interview, and, the semi-structured or semi- standardized interview. The third type of interview (semi-structured or semi-standardized) was selected for this research. Berg (p.17) stated that this kind of interview is systematic and consistent in order and, it allows sufficient freedom to the interviewer to digress and probe far beyond the responses of the interviewees to the structured questions. In addition, this type of interview permits adaptability in asking questions to gain deeper insights into the issues being explored. It was ensured that all the questions were clear in wording and idea, precise and motivating (Denzin, 1989).

To achieve the research objectives of this study, twelve faculty members were selected for a semi structured interview. Those faculty members were selected who had had most vast experience of teaching English at International level and who had experience of teaching in many countries. For the analysis of data, themes were identified in the interview responses and reported thereon in his study. The interviews were audio recorded and were transcribed the earliest possible time. The earlier interviews provided some additional points that were added in the subsequent interviews. For the purpose of observing research ethics, the names of participants were kept secret. Hence the twelve participants were pseudonym as R1, R2...R12.

Table 1. Demographic information of the interviewees

\begin{tabular}{cccccc}
\hline $\begin{array}{c}\text { Sr. No./ } \\
\text { Names }\end{array}$ & Country of Origin & Gender & $\begin{array}{c}\text { Academic } \\
\text { Qualification }\end{array}$ & $\begin{array}{c}\text { Teaching } \\
\text { Experience }\end{array}$ & $\begin{array}{c}\text { International Exposure of } \\
\text { teaching }\end{array}$ \\
\hline R 1 & Hungary & Female & Masters & 32 years & $\begin{array}{c}\text { Hungary, UK, Italy, } \\
\text { Austria, USA, KSA } \\
\text { Hungary, Canada, USA, } \\
\text { Mexico, Spain, KSA }\end{array}$ \\
R 3 & Hungary & Male & Masters & 10 years & $\begin{array}{c}\text { Mudan, England, Egypt, } \\
\text { Sung, France, S. Africa }\end{array}$ \\
R 4 & Sudan & Male & Ph.D & 19 years & Kenyan, Kuwait, KSA \\
R 5 & India & Male & Ph.D & 15 years & $\begin{array}{c}\text { India, Russia, France, KSA } \\
\text { India, Nepal, KSA }\end{array}$ \\
R 6 & India & Male & Ph.D & 20 years & India, England, Canada, \\
& India & Male & Masters & 10 years & France, UAE, KSA \\
\hline
\end{tabular}




\begin{tabular}{|c|c|c|c|c|c|}
\hline R 7 & Pakistan & Female & Masters & 08 years & Pakistan, KSA \\
\hline R 8 & Pakistan & Male & Masters & 12 years & Pakistan, UAE, KSA \\
\hline R 9 & Yemen & Male & Ph.D & 15 years & Yemen, Oman, KSA \\
\hline R 10 & Yemen & Male & Ph.D & 20 years & $\begin{array}{l}\text { Yemen, Egypt, Turkey, } \\
\text { France, Belgium, KSA }\end{array}$ \\
\hline R 11 & Bangladesh & Male & Masters & 17 years & $\begin{array}{l}\text { Bangladesh, Switzerland, } \\
\text { Germany, USA, UK, KSA }\end{array}$ \\
\hline R 12 & Senegal & Male & Masters & 26 years & $\begin{array}{c}\text { Senegal, USA, Spain. } \\
\text { Gambia. KSA }\end{array}$ \\
\hline
\end{tabular}

\section{Teachers' role in ICC}

The teaching experience/s, origin and the pre-existing set of knowledge in teachers affect significantly their teaching in the new contexts. The English language teachers have to prepare themselves for a cross-cultural learners' purpose. But unfortunately it has been observed that the traditional Teacher Training programs in some countries do not prepare teachers well for an international exposure, as some of the interview participants expressed this feeling. Teachers' training programs should include courses for ICC training to the prospective teachers. As McKay (2003) argues that the teachers need to build up in their personality a sphere or interculturality in EIL classrooms so that (the) individuals gain insight into their own culture. These insights can then be shared in cross-cultural encounters undertaken in international contexts. She is of the opinion that the native models should not dictate the teaching methodologies used in EIL. She believes that it rather be replaced with one that recognizes that individual classrooms within one culture can vary greatly in terms of the expected role of the teachers and students. The bilingual teachers should not hesitate in taking the ownership of not only the language itself but the language teaching methodologies they devise to impart knowledge and give practice to the learners, and as a key factor in determining an appropriate methodology is what Prahbu (1987) calls a teacher's sense of plausibility (p 99-104). Almost all of the interviewees shared one feeling that bilingual teachers are more successful in teaching EIL. By the bilingual teachers they mean "those who teach or will be teaching English to individuals who are learning the language alongside one or more languages they speak to communicate with those from another culture and to participate in a growing global community" (Mckay, 2002, p.3). One of the researchers on EIL said, 'given the socio-cultural background, it would not be viable for KSA for using the Inner Circle Standard English as the medium of classroom instructions' (Al-Asmari, 2015).

Most of the interviewees were convinced with the importance of inculcating ICC in the learners. On the question that what is ICC, one of the participants said that:

I think Intercultural competence is the ability to communicate effectively and appropriately with the people of other countries. It is a variable set of behavioral, cognitive and affective skills that supports appropriate interaction in a variety of multi-cultural contexts.

Another participant, who hailed from India, said that intercultural competence in teaching English means to develop in students an understanding the cultural settings in which the language is used in order to learn how to place their culture in contact with the others'. To have a good command of a language does not only mean knowing how to use its grammatical, syntactic and semantic structures but also to develop appropriate ICC skills in the learners. While talking on the context in ELT, one of the participants (from Europe) said:

Context is very important in English teaching. Its (linguistic) meaning is understood not only through what speakers express in words but also through what they do with words to meet the cultural needs of their social environment. It involves socio-linguistic factors where the context of language is an integral part. This contextual use of language is what the teachers of EIL should strive for.

The views of the participants on the teachers' own cultural background differed. One of them said that it is significant for the expatriate teachers to fully conceptualize the cultural factors of the students before going to an ELT classroom. Students develop their understanding of the patterns of language on the basis of their cultural values which sometimes don't match with teachers' attitude in the class room in order to develop rapport with students. ICC in the teachers definitely helps the teachers overcome the unforeseen difficulties which arise in the class room.

Teachers' role is no doubt the most crucial factor for teaching EIL (McKay, 2003). Teachers' pre-existing frames of knowledge and training play an important role in adapting to EIL. A participant who hailed from Pakistan said that:

With advancing experience of ELT, teachers normally tend to impose their own set of anecdotes and beliefs on students which help teachers to maintain pleasant and learning atmosphere in the classrooms, barring occasional misunderstanding for the students because of their lack of empathy. 
The teachers have to prepare themselves for a myriad roles in class room. As Renandiya (2012) on counting the roles of an EIL-oriented teacher, also says that the traditional roles of being a lecturer, mentor of the class, monitor and supervisor of the class room activities, material developer, needs analyst, motivator, provider of the language in-put, etc., is not enough; what further he is supposed to do is to promote ICC and multi-culturalism in the students he is dealing with, promote the other varieties of English (instead of a native English speaker model), critically use the course books and the so-called successful teaching methodologies (p. 65). He further argues that:

"To implement an EIL approach, the teachers need to learn and do a lot of things - they need to understand what it means to teach English in the EIL context; they need to know what kinds of roles they should play in promoting EIL pedagogy and what roles they should be critical about if they want to put into practice an approach to teaching English that is compatible with EIL principles; they also need to be willing to learn new knowledge and skills before they can comfortably assume their new roles in teaching EIL... they need to develop a favorable attitude towards the teaching of EIL".

An interviewer, who belonged to Yemen told that cultural misunderstanding between students and ELT teachers is somewhat normal to happen in classrooms, especially during the initial stage of mutual interaction. The teachers must be conscious enough to adapt their own habits, attitude, terminology and methodology to the students' liking and interest in such a way that they become receptive to the learning. Over the time, developing rapport with the students can also prove helpful. He further said that:

All the new teachers must be provided primarily with enough study materials so that they are wellacquainted with the cultural tenets of the targeted students to avoid any possible blunders during teaching. They must be trained to manage and control the behavioral patterns of the students showing or citing a few examples that caused a lot of unpredictable confusion or impediments for the teachers in the past.

\section{Students' Motivation}

The teacher's role as a motivator for the learning process is crucial. It is a well-established fact now that motivation plays very important role towards learning a target language. A plethora of research on this topic suggests that the correlation between motivational level among students and their success on learning new chunks of language is constantly positive. A well-known Psychiatrist Dornyei (2001, as quoted in Renandiya, 2012) said: ... during the lengthy and often tedious process of mastering a foreign/second language (L2), the learner's enthusiasm, commitment and persistence are key determinants of success or failure (p. 5). Rinandiya (2012, referring to Wlodkowski, 1999) argues that "motivated learners are enthusiastic, goal-orientated, committed, persistent and confident learners. They are willing to work hard to achieve their goal and do not easily give up until they achieve that... they are more attentive during lessons, they take notes to help them to retain information, they ask questions when the teachers' explanation is not clear and they reflect on their understanding of the lesson". One interviewee said that:

Effective application of teachers' knowledge, skills and attributes is a major challenge for ELT in Saudi context, keeping in view the missing motivational factors among the students. The external circumstances don't lead them to be inspired enough to work hard for a language which apparently they don't foresee to use in future, unless they nurture ambition to settle in a western English speaking country for higher education or professional prospects. Arabic's ubiquity all over the country from rural parts to urban areas usually leave them in a comfortable zone hoping for a bright future.

\section{Conclusion}

Teaching EIL in KSA is indispensable in the light of above discussion. English has proved a milestone in the uplift of social and economic fronts in the kingdom since 1925 when it was first introduced in the government curriculum through the Ministry of Education (Al-Ahadib, 1986). The text books should be made localized. It is not easy to define the concepts of Halloween, Christmas, drinking alcohol and Dating with girls/boys, etc. to the Saudi students, rather than they need a 'discursive and multimodal features of Saudi English that (is) much more locally oriented and reflect local cultural norms and practices... an English (that) reflects recognisably local cultural, religious and social values and beliefs' (Mehboob and Elyas, 2014- p.128).

This case study shows that Jazan University meets one of the criterion of teaching EIL, i.e. its faculty members who hail from various parts of the world, carrying multiple sets of cultural knowledge with them. Most of the teachers have quite significantly multi-dimensional and varied fields of specialization like Applied Linguistics, Language Education, Translation, Educational Psychology, Literature, etc. They are well qualified as indicated in the demographic part of this paper. They have myriad experiences of teaching in many countries and cultural settings. They are willing, as they expressed during data collection, to incorporate ICC in the learners as they recognize its importance in teaching EIL. The need is to revise the curriculum in accordance with the objectives of teaching EIL for inculcating in the minds of the learners ICC. This study also suggests that the teachers' training programs around the world should include ICC element in their syllabi keeping in view the fact that mobility of English teachers around the world exceeds than any other fraction of society moving from country to country in this context. 


\section{References}

Ahmad, S. \& Rao, C. (2012). "Does it Work? Implementing Communicative Language Teaching Approach in EFL Context", in Journal of Education and Practice, 3(12), 28-35.

Alptekin, C. (2002). Toward Intercultural Communicative Competence in ELT. ELT Journal, 56(1),57-64.

Al-Ahaydib, M. E. (1986). Teaching English as a Foreign Language in the Intermediate and Secondary Schools of Saudi Arabia: Diagnostic Study. (Unpublished PhD thesis). Kansas: University of Kansas.

Al-Asmari, A.M. \& Khan, R.M.S. (2015). "World English in the EFL Teaching in Saudi Arabia", in Arab World English Journal, 5(1), 316-325.

Al-Hajailan, T. (2003). Teaching English in Saudi Arabia. Riyadh: Dar Al-Sawlatia.

Al-Miziny, H. (2010). The abducting of education in Saudi Arabia. .Alkhatlaf Attalim fil Saudia, Beirut: Arab Diffusion Company.

Al-Seghayer, K. (2005). Teaching English in the Kingdom of Saudi Arabia, In G. Braine (ed.), Teaching English to the World: History, Curriculum, and Practice, 65-78. Mahwah, NJ: Lawrence Erlbaum Associates.

Berg, B. L. (1989). Qualitative research methods for the social sciences. Boston: Allyn \& Bacon.

Canale, M. (1983). "From communicative competence to communicative language pedagogy", in J. C. Richards and R. W. Schmidt (eds.). Language and communication. London: Longman.

Chomsky, N. (1957). Syntactic Structure. MIT Press: Cambridge, MA, USA.

Dana, M.C. (2010). Teaching English in a Multicultural Society: Three Models of Reform. Canadian Journal of Education, 33(2), 432-458.

Denzin, N. K. (1989). Interpretive biography. Newbury Park, CA: Sage

Dimensions International (2014). A Periodical of Saudi Aramco, retrieved online from www.saudiaramco.com/content/dam/.../Dimension_Winter2014.pdf on 19.05.2015.

Dornyei, Z. (2001). Motivational Strategies in the Language Classroom, Cambridge: Cambridge University Press.

Holliday, A. (2006). Native-speakerism. ELT Journal, 60(4), 385-387.

Hymes, D. (1971). On communicative competence, Philadelphia, PA: University of Pennsylvania Press.

Kachru, B. (1992). World Englishes: approaches, issues and resources. Language Teaching, 25: 1-14. Cambridge UP.

Karmani, S. ( 2006). Islam, English, and 9/11: An Interview with Alistair Pennycook. Retrieved online on March 2,

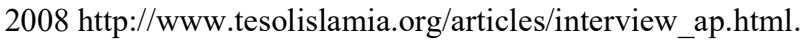

Larsen-Freeman, D. (2000). Techniques and principles in language teaching. Oxford: Oxford University Press.

Lincoln, Y.S., \& Guba, E.G. (1985) Naturalistic Inquiry. Beverly Hills, C.A: Sage.

Mahboob, A. and Elyas, T. (2014). English in the Kingdom of Saudi Arabia. World Englishes, 33(1), $128-142$.

McKay, S. L. (2003). Toward an Appropriate EIL Pedagogy: Re-examining Common ELT Assumptions. International Journal of Applied Linguistics, 13(1), 1-22.

McKay, S.L. (2002). Teaching English as an International Language: Rethinking Goals and Perspectives, New York: Oxford University Press.

Prabhu, N.S. (1987). Second Language Pedagogy, Oxford University Press.

Rinandiya, W.A. (2012). Teacher Roles in EIL. The European Journal of Applied Linguistics and TEFL, 65-80.

Seidlhofer, B. (2004). Research Perspectives on Teaching English as a Lingua Franca. Annual Review of Applied Linguistics, 24, 209-239.

Sharifian, F. (2013). Globalisation and developing metacultural competence in learning English as an International Language. Multilingual Education, 3(7). Retrieved from http://www.multilingual-education.com/content/3/1/7 on 16.05.2015.

Sharifian, F. (2009). English as an International Language: An Overview, English as an International Language, Perspectives and Pedagogical Issues, Multilingual Matters (Handbook) retrieved on 24.05.2015 from https://books.google.com.sa/books?id=6zArJ1ZBBpEC\&printsec=frontcover\#v=onepage \&q\&f=false.

Sifakis, N. C. (2004). Teaching EIL-Teaching International or Intercultural English? What Teachers Should Know, System 32, 237-250.

Wagner, D. \& Cafiero, G. (2014). Is the U.S. losing Saudi Arabia to China? Online post retrieved from http://www.huffingtonpost.com/daniel-wagner/is-the-us-losing-saudi-ar_b_4176729.html on 19.05.2015.

Wlodkowski, R. J. (1999). Enhancing Adult Motivation to Learn. San Francisco, CA: Jossey-Bass Publishers. 